\title{
Selenium enhances the efficacy of Radachlorin mediated- photodynamic therapy in TC-1 tumor development
}

\author{
YONG-WAN KIM ${ }^{1}$, SU MI BAE ${ }^{1}$, HAI-BO LIU ${ }^{1}$, IN-WOOK KIM ${ }^{1}$, \\ HEUNG-JAE CHUN ${ }^{2}$ and WOONG SHICK AHN ${ }^{3}$ \\ ${ }^{1}$ Catholic Research Institutes of Medical Science, ${ }^{2}$ Institute of Cell and Tissue Engineering \\ and ${ }^{3}$ Department of Obstetrics and Gynecology, College of Medicine, \\ The Catholic University of Korea, Seoul, Republic of Korea
}

Received January 17, 2012; Accepted March 9, 2012

DOI: $10.3892 /$ or.2012.1820

\begin{abstract}
Selenium, an essential trace element possessing anticarcinogenic properties, can induce apoptosis in cancer cells. Our goal was to investigate the enhanced antitumor effects of photodynamic therapy (PDT) plus selenium in TC-1 tumor cells and implanted mice. Cell viability was evaluated at various time intervals after PDT treatment and/or selenium by methyl thiazolyl tetrazolium (MTT) assay. When only PDT treatment was administered to TC-1 tumor cells, TC-1 cell growth recovered over time. On the other hand, co-treatment of PDT and selenium extended the inhibition time of tumor cell growth. Co-treatment of PDT and selenium showed serious morphological changes in TC-1 cells and induced a more apoptotic population by FACS analysis. By signal transduction pathway SuperArray analysis, genes closely involved in the NFKB, p53 and phopholipase C pathways, such as VCAM1, MDM2 and FOS, were significantly downregulated at least 10 -fold in TC-1 cells following PDT and selenium cotreatment. In an in vivo study, tumor-bearing mice were intravenously injected with Radachlorin $3 \mathrm{~h}$ before irradiation with $300 \mathrm{~J} / \mathrm{cm}^{2}$ of light. Selenium was administered daily for 20 days. Combination therapy against the mouse tumors generated by TC-1 cells was more effective than PDT or selenium alone. These data suggest that selenium plus PDT can induce a significant tumor suppression response compared with PDT alone. Additionally, it can be an effective anticancer therapy strategy.
\end{abstract}

\section{Introduction}

Photodynamic therapy (PDT) is an oxygen-mediated, minimally invasive therapeutic modality. It involves the administration of a tumor-localizing photosensitizer that is subsequently activated with light of a specific wavelength, thus causing highly selec-

Correspondence to: Dr Woong Shick Ahn, Department of Obstetrics and Gynecology, College of Medicine, The Catholic University of Korea, 505 Banpodong, Seocho-ku, Seoul 137-040, Republic of Korea E-mail:ahnlab1@catholic.ac.kr

Key words: photodynamic therapy, selenium, combination therapy, anti-cancer therapy tive photodynamic destruction of tumor cells. The evident advantage of PDT over other conventional cancer treatments such as chemotherapy and radiotherapy is its minimal invasiveness, selective targeting, and reduced toxicity, which allows for repeated treatment (1). Currently, PDT is being successfully used for the treatment of early lung cancers $(2,3)$ and in dermatology for the treatment of non-melanoma skin cancers and precancerous diseases (4). PDT has also been successfully employed to treat early carcinomas of the oral cavity and larynx to preserve normal tissue and improve cure rates (5). Though therapeutic responses are encouraging, recurrences have been noticed due to incomplete PDT, which consequently triggers tumor angiogenesis. Non-homogeneous light distribution, incomplete photosensitizer dosage, and tissue/tumor dynamics are some of the factors that impose constraints on the efficacy of PDT. Moreover, as PDT-induced oxidative stress can cause hypoxic conditions in the surviving tumor cells, it can elicit the expression of angiogenic growth factors and cytokines as an adaptive response $(6,7)$. Hypoxia is also known to reduce tumor sensitivity to radiation therapy and chemotherapy that is associated with decreased local tumor control $(8,9)$. Thus, further study of controlling unwanted growth-stimulatory pathways after PDT is desirable to minimize the risk of harmful adverse effects.

Selenium is an important antioxidant nutrient that supports the production of enzymes that protect cells against oxidant stress (10). Since oxidants can damage DNA, leading to potentially carcinogenic mutations, good selenium status has clearly anti-mutagenic potential. Epidemiological studies have pointed to the decrease of risks for certain cancers in people who have relatively high selenium intakes or who live in regions of the world where soil selenium levels are relatively high. The anticarcinogenic effects of selenium against leukemia and cancers of the colon, rectum, pancreas, breasts, ovaries, prostate, bladder, lung, and skin have been reported (11). Anti-carcinogenic mechanisms in various cancers are related to reactive oxygen species (ROS) produced by redox cycling, modification of protein-thiols, and methionine mimicry. Principal selenium metabolites, such as hydrogen selenide, methylselenol, and selenomethionine execute anti-carcinogenic effects (12). Selenium compounds also can cause acute toxicity due to DNA strand breaks by generating superoxide at high concentrations of mainly inorganic forms. But many studies using different 
forms and doses of selenium have been reported; selenium doses involved in chemoprevention and tumor growth inhibition remain to be elucidated (13).

To induce effective anti-tumor response with low adverse effects, we attempted to co-treat with PDT and selenium. Combination therapy using low concentrations of photosensitizer and selenium may effectively reduce angiogenesis and recurrence of cancer cells by PDT and selenium toxicity at a high concentration. Additionally, apoptosis of cancer cells and continuous inhibition of cancer cell development may be induced more effectively.

\section{Materials and methods}

Ethics statement. All procedure of animal research were provided in accordance with the Laboratory Animals Welfare Act, the Guide for the Care and Use of Laboratory Animals and the Guidelines and Policies for Rodent experiment provided by the IACUC (Institutional Animal Care and Use Committee) in School of Medicine, The Catholic University of Korea (permit no: CUMC-2008-0062-02).

Cell culture and tumor model. A murine cell line, TC-1 (ATCC CRL-2785) was cotransformed by HPV-16 E6/E7 oncoproteins and c-Has-Ras and was cultured in RPMI-1640 medium (Gibco BRL, Rocksville, MD) supplemented with $5 \%$ fetal bovine serum (FBS; Gibco BRL). Streptomycin/penicillin (Gibco BRL), L-glutamine (Gibco BRL), $2.2 \mathrm{mg} / \mathrm{ml}$ sodium bicarbonate (Sigma, St. Louis, MO), and $0.4 \mathrm{mg} / \mathrm{ml}$ G418 disulfate (Duchefa, The Netherlands) were added to the culture medium, and the cells were maintained at $37^{\circ} \mathrm{C}$ in a $5 \% \mathrm{CO}_{2}$ humid environment.

Specific pathogen-free female C57BL/6 mice 6-7 weeks of age were purchased from Orient Bio (Seongnam, Korea) and maintained in the specific pathogen-free animal facility. Five to six mice were housed per cage under standard conditions. Mice were fed standard laboratory chow and water. The depilated lower dorsa of the mice were injected subcutaneously with $5 \times 10^{5}$ TC-1 cells to generate the tumor model. Tumor growth was documented regularly by Vanier calipers in three orthogonal dimensions. Tumors were used for experimentation 10-12 days after inoculation when reaching surface diameters of 10-12 mm and thicknesses of 5-6 $\mathrm{mm}$.

Photodynamic theraphy (PDT) and selenium treatment. The photosensitizer, Radachorin, was purchased from RADAPHARMA group (RADA-PHARMA, Moscow, Russia) and was diluted in PBS buffer to make a $1 \mathrm{mg} / \mathrm{ml}$ stock solution. The light source was a diode laser with a $662 \pm 2 \mathrm{~nm}$ wavelength (ALOD-01, Alcom Medica Ltd., St.-Petersburg, Russia). TC-1 cells were treated with Radachlorin $(0.1,0.15$, or $0.2 \mu \mathrm{g} / \mathrm{ml})$ for $12 \mathrm{~h}$. Cells were washed with PBS buffer and then irradiated with $6.25 \mathrm{~J} / \mathrm{cm}^{2}$ of light. Selenious acid (SELA, Sigma) was dissolved in PBS buffer and filter-sterilized.

MTT assay. Cell proliferation was determined using the methyl thiazolyl tetrazolium (MTT) assay. TC-1 cells were subjected to PDT, selenium, or PDT plus selenium and further incubated at $37^{\circ} \mathrm{C}$ and $5 \% \mathrm{CO}_{2}$ in a humidified incubator. After incubation, MTT solution was added to each well. After $4 \mathrm{~h}$, DMSO was added, and then absorbance was measured at $670 \mathrm{~nm}$ in an automated spectrophotometer microtiter plate reader (Spectra Max 340, Molecular Devices, CA, USA).

Flow cytometry analysis. For cell cycle analysis, propidium iodide (PI) staining was performed. Cells were collected, washed twice with PBS, and then re-suspended in PI buffer $(0.1 \%$ sodium citrate, Triton X-100, and $5 \mu \mathrm{g} / \mathrm{ml}$ propidium iodide). RNase A $(250 \mu \mathrm{g} / \mathrm{ml})$ was added to each cell sample, and the cells were stained for $10 \mathrm{~min}$ in the dark. Flow cytometry was performed on a FACScan automated system (Becton-Dickinson, Sunnyvale, CA, USA), and data were analyzed using the CellQuest software package and ModFit LT 2.0 program.

To determine apoptosis of TC-1 cells following treatments of PDT and/or selenium, TC-1 cells were collected at $48 \mathrm{~h}$ after all treatments and washed twice with PBS. The cells were stained with PI and annexin V-FITC. Annexin V-FITC staining was performed with an apoptosis detection kit (Invitrogen, Camarillo, CA, USA) as described by the manufacturer's instructions. The cells were analyzed using a FACScan flow cytometer (Becton-Dickinson) at $488 \mathrm{~nm}$ laser light excitation. The cell populations were observed in a dot plot graphic. The population of apoptotic cells was represented as annexin V-positive and PI-negative cells, the population of necrotic cells was represented as annexin V-negative and PI-positive cells, and the population of late apoptotic/necrotic cells were represented as annexin V-positive and PI-positive cells.

Real-time quantitative PCR $(Q P C R) /$ microarray analysis. Total RNA was isolated using TRIzol (Invitrogen Life Technologies, Carlsbad, CA) from TC-1 cells previously treated with PDT, selenium, or PDT plus selenium for $48 \mathrm{~h}$. Reverse transcription was performed using the RT2-First Strand Kit (SuperArray Bioscience Corp., Frederick, MD) according to the manufacturer's protocol. Gene profiling was performed using the RT2-profiler PCR array Mouse Signal Transduction Pathway Finder PCR Array (89 genes including 5 housekeeping genes). The reactions were carried out in a Stratagene Mx 3000P realtime PCR system (Stratagene, La Jolla, CA). The values were obtained for the threshold cycle $\left(C_{t}\right)$ for each gene and normalized using the average of the 5 housekeeping genes on the same array. The resulting values were reported as fold change; only genes showing 3 -fold or greater change were considered.

Statistical analyses. Genes that showed differences in their expression levels $\geq 3.0$ fold, were selected for analyses (gene ontology analysis, hierarchical cluster analysis, functional cluster analysis, biological pathway analysis). Hierarchical clustering (Gene Cluster v3.0) and display programs (TreeView) were also used for analysis (http://rana.stanford.edu/software). We performed unsupervised hierarchical clustering based on the most variably expressed genes using the Euclidean distance as the similarity metric and the average linkage method as the between-cluster distance metric. A t-test was also performed to find genes that had changed between PDT alone and selenium alone, and PDT plus selenium treatment. Supervised clustering of experimental samples was performed by reducing the number of genes by statistical analysis. To classify the gene expression profiles, functional analyses and KEGG (Kyoto Encyclopedia for Genes and Genomes) pathway analyses (http://www.genome. $\mathrm{jp} / \mathrm{kegg} / \mathrm{pathway.html)}$ were carried out as previously described 
A
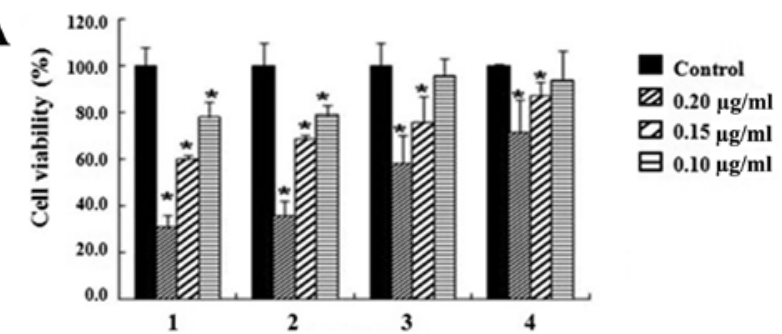

B
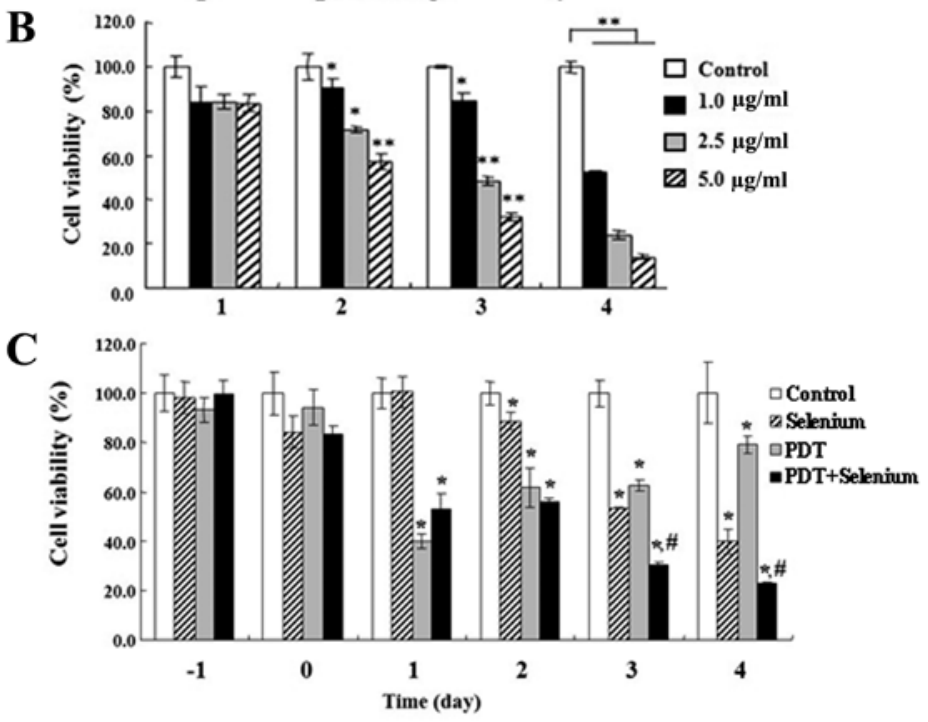

Figure 1. Cell viability of TC-1 cells by Radachlorin PDT and selenium. TC-1 cells were treated with different doses of Radachlorin for PDT $\left(6.25 \mathrm{~J} / \mathrm{cm}^{2}\right)(\mathrm{A})$ and various doses of selenium (B) for 4 days. Cell viability was determined based on the MTT assay as indicated in Materials and methods (columns: bars, SD; ${ }^{*} \mathrm{P}<0.05$ and ${ }^{* *} \mathrm{P}<0.001$ compared with the control, by Student's t-test). (C) Cell growth inhibitory effects of Radachlorin PDT plus selenium on TC-1 tumor cell lines. Radachlorin PDT $\left(0.15 \mu \mathrm{g} / \mathrm{ml}, 6.25 \mathrm{~J} / \mathrm{cm}^{2}\right)$ and selenium $(1 \mu \mathrm{g} / \mathrm{ml})$ were administered together to TC-1 cells for 4 days. Cell viability was determined by MTT assay (columns: bars, SD; "P<0.05 compared with control; ${ }^{*} \mathrm{P}<0.05$ compared with the PDT group by Student's t-test).

$(14,15)$. To perform a KEGG analysis, differentially expressed genes of each treatment group were used for the calculation of their attribution to pre-defined KEGG signaling pathways and analyzed by pair-wise comparisons. Different number of genes were seen in a given pathway. The Ingenuity Pathway Analysis software (IPA, Ingenuity Systems, Mountain View, CA) was utilized to identify networks of interacting genes and other gene ontology functional groups. The significantly up-regulated and down-regulated functional activities were analyzed according to the biological processes, cellular components and molecular function ontology. Semantically consistent pathway relationships were modeled based on a continual, formal extraction from the public domain literature (www.ingenuity.com/products/pathways_knowledge.html).

Measurement of tumor size in TC-1 cells implanted in C57BL/6 mice. Mice were divided into 4 groups of at least 5 animals per group. Tumor-bearing mice were given intravenous and intraperitoneal injections of Radachlorin and selenium, respectively. The first group was treated with selenium (dose: $2 \mu \mathrm{g} / \mathrm{kg}$ body weight), the second group was treated with Radachlorin (dose: $10 \mathrm{mg} / \mathrm{kg}$ ), and the third group was treated with both Radachlorin and selenium. The final two groups were untreated controls. When tumors were $\sim 8-10 \mathrm{~mm}$ in mean tumor diameter, Radachlorin $(10 \mathrm{mg} / \mathrm{kg})$ was injected into the tail veins of mice $3 \mathrm{~h}$ before irradiation. The tumor was irradiated at a fluence of $300 \mathrm{~J} / \mathrm{cm}^{2}$. Following light treatment, selenum was given daily by intraperitoneal injection $(2 \mu \mathrm{g} / \mathrm{kg}$ bw).
One control group was only irradiated (no administration of photosensitizer), and the other did not receive any photosensitizer or irradiation. The mice were maintained, and the tumor volumes were measured at two or three day intervals for 23 days. Tumor growth was measured twice a week using calipers and recorded as volume diameter [longest surface length (a), width (b), and height (c), a x b x c].

Statistical analysis. Statistical analysis included ANOVA and the Student's t-test. The values for the different groups were compared. P-values of less than 0.05 or 0.01 were considered significant.

\section{Results}

Growth inhibitory effect in tumor cells by PDT, selenium, or PDT plus selenium. We performed cell viability assays (MTT assays) to examine effects of PDT in growth inhibition of TC-1 cells. TC-1 tumor cells were treated with various concentrations of Radachlorin as a photosensitizer and maintained for $12 \mathrm{~h}$. The cells were washed with PBS and then irradiated by $6.25 \mathrm{~J} / \mathrm{cm}^{2}$ of light with a $662 \pm 2 \mathrm{~nm}$ wavelength emitted from a diode laser. Cell viability was determined by MTT assay. TC-1 cell growth was significantly inhibited in a Radachlorin dose-dependent manner. However, the cell growth that was inhibited by PDT recovered over time after 3-4 days (Fig. 1A). In particular, at 4 days after PDT therapy, growth of TC- 1 cells treated with $1 \mu \mathrm{g} / \mathrm{ml}$ Radachlorin PDT recovered up to $\sim 90 \%$. We examined 

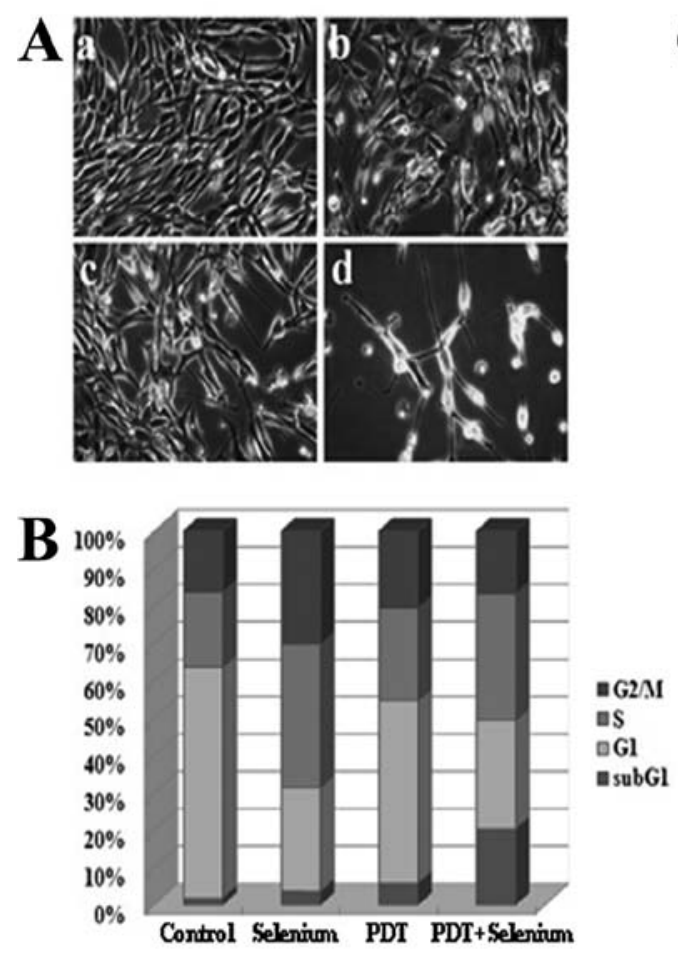

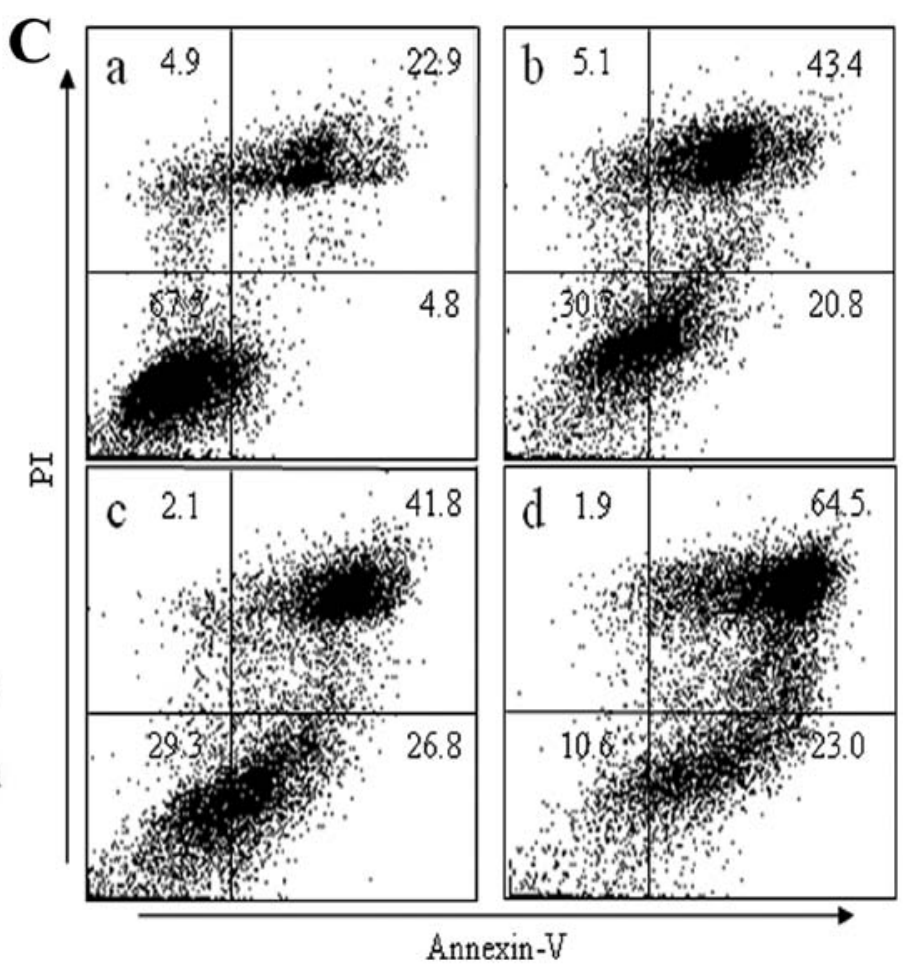

Figure 2. Combination effects of Radachlorin PDT and selenium in apoptosis of TC-1 tumor cells. (A) Morphological change of TC-1 cell lines. TC-1 cells were treated with $0.15 \mu \mathrm{g} / \mathrm{ml}$ Radachlorin PDT and/or $1 \mu \mathrm{g} / \mathrm{ml}$ selenium for 2 days as described in Materials and methods. Cells were observed under a microscope and photographed at x300 (a, non-treated; b, $0.15 \mu \mathrm{g} / \mathrm{ml}$ Radachlorin PDT; c, $1 \mu \mathrm{g} / \mathrm{ml}$ selenium; $\mathrm{d}, 0.15 \mu \mathrm{g} / \mathrm{ml}$ Radachlorin PDT plus $1 \mu \mathrm{g} / \mathrm{ml}$ selenium). (B) Cell cycle analysis of TC-1 cells following the Radachlorin PDT and/or selenium treatments by FACS. TC-1 cells were cultured with Radachlorin PDT $\left(0.15 \mu \mathrm{g} / \mathrm{ml}, 6.25 \mathrm{~J} / \mathrm{cm}^{2}\right)$ and/or selenium for 4 days. Cell pellets were then washed once in ice-cold HEPES buffer and propidium iodide (PI) staining dye was added and incubated in the dark for $15 \mathrm{~min}$. (C) Detection of TC-1 apoptosis using FACS analysis. Cells were exposed to Radachlorin PDT (0.15 $\mu \mathrm{g} /$ $\left.\mathrm{ml}, 6.25 \mathrm{~J} / \mathrm{cm}^{2}\right)$, selenium $(1 \mu \mathrm{g} / \mathrm{ml})$ and Radachlorin PDT plus selenium for 2 days. The cells were stained with PI and annexin V-FITC and analyzed with a flow cytometer. Percentage (\%) of each cell population was determined.

the effect of selenium in TC-1 cell growth inhibition. Selenium is known to possess anticancer properties at low concentration, but it can be genotoxic and possibly carcinogenic at high concentrations. TC-1 cell growth was determined by MTT assay for different concentrations of selenium (Fig. 1B). TC-1 cell growth was significantly suppressed in a selenium dose-dependent manner, and cell growth recovery was not observed, unlike that seen with PDT administration.

To effectively inhibit TC-1 growth using the benefits of PDT and selenium treatment, we attempted combination therapy consisting of PDT treatment with a low concentrations of both Radachlorin and selenium. TC-1 cells incubated with $0.15 \mu \mathrm{g} /$ $\mathrm{ml}$ Radachlorin for $24 \mathrm{~h}$, and selenium $(1 \mu \mathrm{g} / \mathrm{ml})$ were added to the cultured medium immediately before light treatment. Co-treatment of PDT plus selenium significantly reduced TC-1 cell growth compared to PDT or selenium alone (Fig. 1C). Despite the low concentrations of Radachlorin and selenium, TC-1 cell growth was continuously inhibited according to time, and growth recovery of TC-1 cells after PDT was not observed at 3 and 4 days after treatment. These results indicate that co-treatment of PDT and selenium is able to effectively suppress growth of TC-1 tumor cells.

Apoptotic morphology of TC-1 cells by co-treatment with PDT and selenium. We characterized TC-1 cell growth inhibition by co-treatment of PDT and selenium. TC-1 cells were treated with $0.15 \mu \mathrm{g} / \mathrm{ml}$ Radachlorin PDT and/or $1 \mu \mathrm{g} / \mathrm{ml}$ selenium for 2 days.
The cell morphology was observed by microscopy (Fig. 2A). TC-1 cell growth was more inhibited with co-treatment of PDT and selenium than PDT or selenium alone. Co-treatment of PDT and selenium more greatly induced the distorted morphology of TC-1 cells and generated many apoptotic bodies. We performed cell cycle analysis to identify the cell cycle distribution (Fig. 2B). The proportion of cells in the sub-G1 phase increased in TC-1 cells following co-treatment with PDT and selenium compared with those treated with PDT or selenium alone. To ascertain whether TC-1 tumor cells were apoptotically induced by combination treatment, we performed FACS analysis after TC-1 cells were treated with $0.15 \mu \mathrm{g} / \mathrm{ml}$ Radachlorin PDT and/or $1 \mu \mathrm{g}$ / $\mathrm{ml}$ of selenium for 2 days (Fig. 2C). The proportion of cells in apoptosis was significantly higher in TC-1 cells following the combination treatment of PDT plus selenium compared to either single therapy. These data show that combination treatment induces a higher level of apoptosis in TC-1 tumor cells compared with treatment of PDT or selenium alone.

Change in gene expression of TC-1 cells by combination therapy. Apoptosis, the process of programmed cell death in eukaryotic cells, causes expression changes in various genes, as well as changes in cell morphology. Therefore, we performed real-time reverse transcription PCR assays to identify genes with significant changes in expression in TC-1 cells treated with PDT plus selenium. Co-treatment of PDT plus selenium compared with treatment of PDT or selenium alone induced 
Table I. Relative expression of target genes in TC- 1 cells.

\begin{tabular}{|c|c|c|c|}
\hline \multirow[b]{2}{*}{ Gene symbol } & \multicolumn{3}{|c|}{ Fold change } \\
\hline & Selenium & PDT & PDT + selenium \\
\hline ATF2 & -1.1 & -1.8 & -9.5 \\
\hline BCL2 & -1.2 & -2.0 & -5.7 \\
\hline NAIP1 & 6.4 & -1.2 & 24.4 \\
\hline BIRC2 & -3.4 & -2.7 & -84.0 \\
\hline BIRC3 & -2.4 & -3.6 & -19.9 \\
\hline BMP2 & -1.3 & 1.4 & -3.4 \\
\hline BRCA1 & -1.8 & -3.5 & -10.7 \\
\hline CCL2 & -3.6 & -1.9 & -3748.3 \\
\hline CCND1 & -1.0 & 1.4 & -3.7 \\
\hline CD5 & 7.8 & 1.1 & 34.5 \\
\hline CDH1 & 4.2 & -1.6 & 20.6 \\
\hline CSF2 & 3.2 & 4.9 & 14.8 \\
\hline CXCL1 & 4.8 & 1.4 & 1.5 \\
\hline CXCL9 & 8.3 & -1.2 & 16.5 \\
\hline CYP19A1 & 4.9 & -1.2 & 46.8 \\
\hline EGR1 & -2.1 & -2.0 & -3.9 \\
\hline FAS & -1.3 & -2.6 & -5.5 \\
\hline FASN & -1.5 & -1.1 & -3.8 \\
\hline FGF4 & 5.7 & -1.2 & 32.6 \\
\hline FN1 & -2.7 & -4.4 & -9.9 \\
\hline FOS & -1.7 & -1.9 & -1391.1 \\
\hline FOXA2 & 5.2 & -1.2 & 15.1 \\
\hline GREB1 & 5.7 & -1.2 & 26.3 \\
\hline HHIP & 2.1 & -1.3 & 6.2 \\
\hline HK2 & -1.4 & -1.8 & -498.7 \\
\hline HSPB1 & 23.7 & 1.3 & 6.3 \\
\hline ICAM1 & -3.3 & -2.6 & -3.7 \\
\hline IL1A & 10.6 & 1.1 & 16.2 \\
\hline IL2 & 6.0 & 1.1 & 2.2 \\
\hline IL2RA & 4.6 & -1.2 & 13.3 \\
\hline IRF1 & -3.8 & -3.8 & -5.9 \\
\hline LEP & 6.1 & -1.2 & -1.1 \\
\hline LTA & 5.0 & -1.0 & -4.4 \\
\hline MDM2 & 1.0 & -1.3 & -8792.2 \\
\hline MMP10 & 1.5 & 2.7 & -17.2 \\
\hline MMP7 & 7.2 & -1.2 & -1.8 \\
\hline NOS2 & 7.5 & 1.3 & 25.2 \\
\hline NRIP1 & -1.3 & -1.3 & -3.7 \\
\hline PPARG & 4.5 & -1.2 & 10.8 \\
\hline PTGS2 & 1.2 & -1.5 & -1597.9 \\
\hline RBP1 & -1.8 & -2.6 & -3.5 \\
\hline SELE & 5.2 & 5.3 & -1.7 \\
\hline SELP & 8.4 & 1.1 & -3.0 \\
\hline VCAM1 & -1.4 & -2.1 & -10.9 \\
\hline VEGFA & -1.2 & -2.4 & -1642.9 \\
\hline WISP1 & -1.3 & -2.6 & -28.1 \\
\hline WNT1 & 8.5 & 2.0 & -2.3 \\
\hline WNT2 & 3.9 & -1.2 & -1.8 \\
\hline
\end{tabular}

many changes in gene expression in TC-1 cells (Table I). Fold changes were relatively high in TC-1 tumor cells co-treated with PDT plus selenium compared with those treated with PDT or selenium alone. To identify signal transduction pathways related to significantly changed genes by co-treatment, they were classified as shown in Table II. Using the signal transduction pathway SuperArray, FOS, HK2, CCL2, MDM2, PTGS2, VEFGA, VCAM1, BIRC2, and BIRC 3 were very significantly downregulated at least 10 -fold in TC-1 cells following co-treatment. These genes were included in gene groups closely related to the $\mathrm{NF} \kappa \mathrm{B}$, p53, and phospholipase C pathways. Furthermore, MDM2, $\mathrm{BIRC} 2$, and BIRC3 are anti-apoptosis related genes, and FOS, HK2, VCAM1, CCL2, PTGS2, WISP1, MMP10, and WISP1 are tumor survival or promoting genes. Upregulated genes by co-treatment had relatively low fold changes compared with the fold changes of downregulated genes and were related to cell survival and proliferation mechanisms. These results indicate that the combination of PDT plus selenium can induce a significant tumor suppression response. To detect the differences in the functional profiles, KEGG pathway analyses were carried out. The enhanced cell growth inhibition and antitumor effects were significantly related with gene expression levels of focal adhesion, MAPK pathway, cytokine-cytokine interaction, and cell adhesion pathway (Fig. 3A-E). Significantly down-regulated molecular functions for the combination treatment group was focal adhesion pathway. Each representative gene in the pathway was tested by quantitative PCR (Fig. 3G). These included genes coding for PTEN, AKT, p53, p21, VEGF, PTGS2, and MMP2. Jak-STAT pathway was also studied in the gene sets, but not strictly correlated with the enhanced cell growth inhibition (Fig. 3F).

Suppression of tumor development in TC-1 cells implanted in C57L/6 mice. We measured tumor sizes of TC-1 tumor cellimplanted C57BL/6 mice to determine in vivo effects of PDT and selenium combination therapy. TC-1 cell xenografted C57BL/6 mice were grouped in four different groups: control, PDT, selenium, and PDT plus selenium groups (Fig. 4). PDT effectively inhibited in tumor development for a short period (approximately 15 days), but inhibition of tumor growth by PDT seemed to be recovered after $\sim 20$ days. After 20 days, growth rates of tumors following PDT treatment compared with growth rates following selenium treatment were relatively increased. In contrast, combination treatment with PDT plus selenium clearly reduced tumor diameters, and this tumor suppression was maintained for 23 days. This result suggests that combination therapy with PDT plus selenium in the tumor-bearing mouse model is effective for in vivo tumor suppression as well as for in vitro tumor suppression.

\section{Discussion}

Photodynamic therapy (PDT) is a relatively recent clinical treatment applied against patients' lesions, including various cancers, and it has already been recognized as a very promising therapeutic method (16). PDT has been applied to improve early stage disease, including lung cancer, brain cancers, head and neck cancers, and non-oncological disorders, such as age-related macular degeneration (17). However, PDT can cause hypoxic conditions in the surviving tumor cells due to 
Table II. Effects of co-treatment of PDT and selenium in signal transduction pathway.

A, Down-regulated genes $\leq 10$-fold

\begin{tabular}{llcrr}
\hline Related signal pathway & Gene symbol & Selenium & PDT & PDT + selenium \\
\hline Calcium and PKC & FOS & -1.7 & -1.9 & -1391.1 \\
CREB & FOS & -1.7 & -1.9 & -1391.1 \\
Estrogen & BRCA1 & -1.8 & -3.5 & -10.7 \\
Insulin & HK2 & -1.4 & -1.8 & -498.7 \\
Jak/Src & MMP10 & 1.5 & 2.7 & -17.2 \\
LDL & VCAM1 & -1.4 & -10.9 \\
& CCL2 & -3.6 & -1.9 & -3748.3 \\
Mitogenic & FOS & -1.7 & -1391.1 \\
NFאB & VCAM1 & -1.4 & -1.9 & -19.9 \\
& BRIC3 & -2.4 & -2.1 & -84.0 \\
& BRIC2 & -3.4 & -3.6 & -8792.2 \\
P53 & MDM2 & 1.1 & -2.7 & -10.9 \\
PLC & VCAM1 & -1.4 & -1.3 & -1391.1 \\
& FOS & -1.7 & -2.1 & -1597.9 \\
Stress & PTG2 & -1.2 & -1.9 & -1391.1 \\
Wnt & FOS & -1.7 & -1.5 & -28.1 \\
& WISP1 & -1.4 & -1.9 & -1642.9 \\
\hline
\end{tabular}

B, Up-regulated genes $\leq 10$-fold

\begin{tabular}{llccc}
\hline Related signal pathway & Gene symbol & Selenium & PDT & PDT + selenium \\
\hline Selenium Calcium and PKC & CSF2 & 3.2 & 4.9 & 14.8 \\
& IL2RA & 4.6 & -1.18 & 13.34 \\
CREB & CYP19A1 & 4.9 & -1.18 & 46.79 \\
Estrogen & GREB1 & 5.7 & -1.18 & 26.38 \\
Hedgehog & FOXA2 & 5.2 & -1.18 & 15.12 \\
Jak-Stat & NOS2 & 7.5 & 1.3 & 25.25 \\
& CXCL9 & 8.3 & -1.18 & 16.54 \\
LDL & CSF2 & 3.2 & 4.9 & 14.8 \\
NFKB & NOS2 & 7.5 & 1.3 & 25.25 \\
& IL1A & 10.6 & 1.09 & 16.2 \\
PLC & NOS2 & 7.5 & 1.3 & 25.25 \\
Wnt & FGF4 & 5.7 & -1.18 & 32.63 \\
& CDH1 & 4.2 & -1.55 & 20.65 \\
& PPARG & 4.5 & -1.18 & 10.84 \\
\hline
\end{tabular}

oxidative stress induction, and it can elicit tumor recurrence and angiogenesis $(8,9)$. Selenium is a dietary essential trace element with biological roles and possesses anticancer properties (11). However, selenium at low concentrations has anti-carcinogenic properties in multiple cancers, including those of the colon, prostate, breast, ovary, and lung, whereas at high concentrations, selenium can generate reactive oxygen species (ROS), which can induce DNA damage (13). Therefore, we tried combination therapy consisting of PDT and selenium to develop a therapeutic method with low adverse effects. We used the TC- 1 cervical cell line with overexpression of human papilloma virus (HPV), the E6/E7 oncogene, and the Ha-ras oncogene. To prepare the cervical cancer mouse model, the TC-1 cervical cell line was transplanted into C57BL/6 mice. Combination therapy with PDT and selenium was applied both in the TC- 1 cell line in vitro and tumor-bearing C57BL/6 mice in vivo.

TC-1 cell viability was significantly inhibited both in PDT or selenium treatment, but cell growth inhibited by PDT alone recovered over time. We tried to co-treat with Radachlorin PDT plus selenium at low concentrations to prevent adverse effects, 


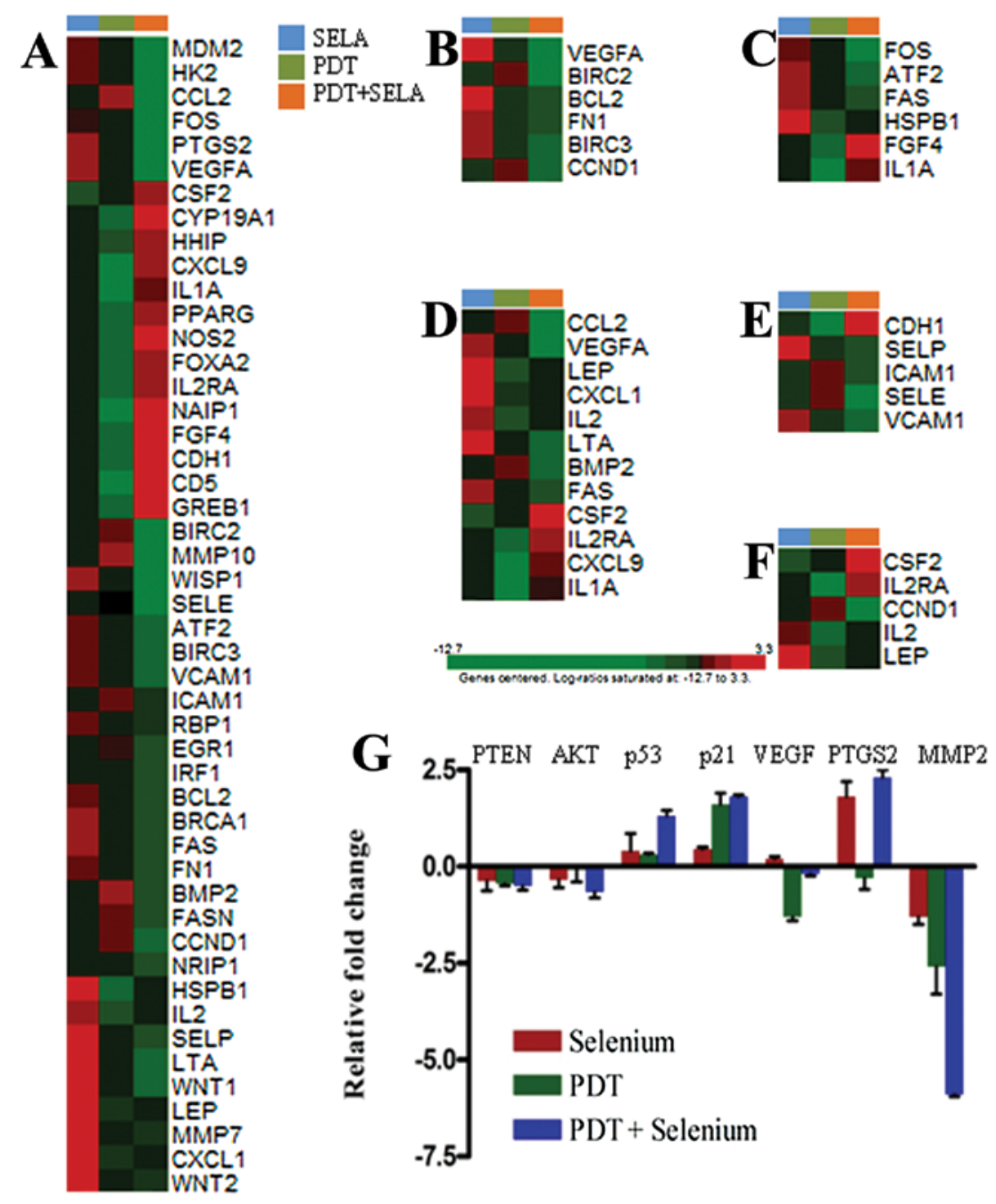

Figure 3. Hierarchical cluster analysis. (A) All the data were median centered and clustered using a hierarchical clustering. A cluster image representing 48 of the genes is shown in matrix format, where rows represent individual genes and columns represent each assay. Each cell in the matrix represents the expression level of a gene in an individual assay. Red and green cells reflect high and low expression levels, respectively. (B) Focal adhesion pathway; (C) MAPK pathway; (D) Cytokine-cytokine receptor interaction pathway; (E) Cell adhesion pathway; (F) Jak-STAT pathway. (G) In vitro gene expression changes of TC-1 cells treated with $0.15 \mu \mathrm{g} / \mathrm{ml}$ Radachlorin PDT and/or $1 \mu \mathrm{g} / \mathrm{ml}$ selenium for 1 day. The expression of genes was examined by Q-PCR. The results are presented as transcript levels relative to the level in untreated control cells.

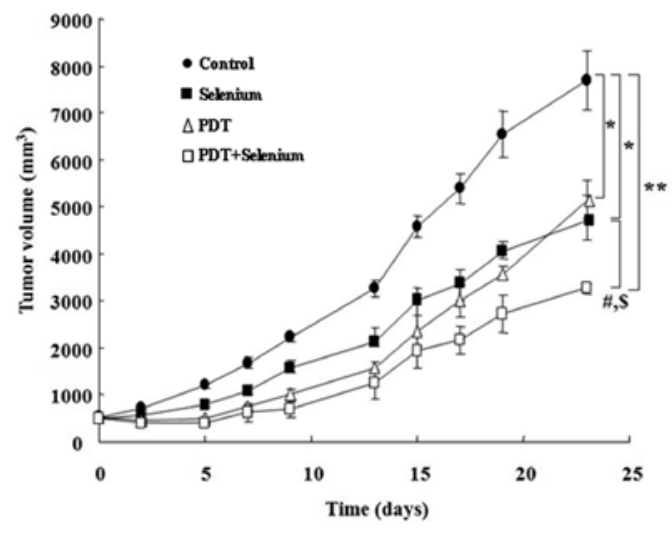

Figure 4. Tumor growth-inhibitory effects of Radachlorin PDT and/or selenium in TC-1 cell-implanted C57BL/6 mice. Each group of mice $(\mathrm{n}=5)$ were challenged s.c. with $2 \times 10^{5} \mathrm{TC}-1$ cells. Tumor-bearing mice were administered PDT and/or peritoneal injections of $2 \mu \mathrm{g} / \mathrm{kg}$ b.w. of selenium for 20 days. For performing PDT, $3 \mathrm{~h}$ after intravenously injected with Radachlorin $(10 \mathrm{mg} / \mathrm{kg}$ $\mathrm{bw})$, tumor sites were exposed to a laser $\left(300 \mathrm{~J} / \mathrm{cm}^{2}\right)$. Tumor size was monitored as described in Materials and methods, and then its mean volume was plotted over time. Significant inhibition of tumor growth was measured by ANOVA. ${ }^{*} \mathrm{P}<0.05$ and ${ }^{* *} \mathrm{P}<0.001$ compared with the control; ${ }^{*} \mathrm{P}<0.05$, compared with Radachlorin PDT and selenium, $\mathrm{P}<0.05$ compared with selenium. such as tumor cell growth recovery and cell toxicity. Despite the low concentrations of Radachlorin PDT and selenium, TC-1 cell growth was effectively inhibited by co-treatment, and cell growth recovery did not occur during the time of the experiment. To determine cell arrest and cell apoptosis by combination therapy, we performed cell cycle and apoptosis analyses using a FACS analyzer. Co-treatment of Radachlorin PDT and selenium compared to Radachlorin PDT or selenium alone induced greater apoptotic TC-1 cell morphology and increased the proportion of TC-1 cells in the sub-G1 phase of the cell cycle. In FACS analysis to confirm TC-1 apoptosis by co-treatment, TC-1 cells following co-treatment were observed to have a larger proportion of annexin V-positive and PI-negative cells in a FACS analysis dot plot graph.

We supposed that combination therapy with Radachlorin PDT and selenium should more effectively inhibit growth of TC-1 cancer through higher TC-1 apoptosis induction. Therefore, we tried to identify genes with significant expression changes as a result of combination treatment. Overall, downregulated genes by co-treatment with PDT and selenium had 
relatively higher fold changes than those of upregulated genes. Co-treatment of PDT and selenium downregulated expression of many genes related to the $\mathrm{NF \kappa B}, \mathrm{p} 53$, and phospholipase $\mathrm{C}$ pathways. These genes included groups of anti-apoptotic and anti-tumor genes. Upregulated genes by co-treatment of PDT plus selenium were related with cell survival and proliferation mechanisms. Upregulation of these genes may be a repair mechanism for various types of damage induced by therapies. Finally, we examined effects of combination therapy in tumor tissue using the TC-1 cell-implanted mouse model. Combination treatment with PDT plus selenium clearly reduced tumor diameters, and this tumor suppression was maintained for a long time.

PDT induces apoptosis by production of singlet oxygen (18), and selenium also induces apoptosis at a low concentration. High concentrations of selenium have pro-oxidant toxicity due to DNA strand breaks, and PDT can cause tumor recurrence and angiogenesis by hypoxic conditions. Therefore, we inspected the results for gene expression change in TC-1 cells following co-treatment with low concentrations of Radachlorin PDT and selenium. Genes with relatively high fold changes in significantly downregulated genes were FOS, HK2, CCL2, MDM2, PTGS2, and VEGFA. FOS, an FBJ murine osteosarcoma viral oncogene homolog, is a transcription factor with oncogenic activity and is frequently overexpressed in various tumor cells (19). HK2, hexokinase II, is known as an enzyme catalyzing the initial metabolic step of glycolysis and is predominantly expressed in many cancer cells. Downregulation of the HK2 gene increases the sensitivity of cancer to anti-cancer agents (20). CCL2, a chemokine (C-C motif) ligand 2, is known as a chemoattractant for monocytes and is expressed in at least nine of ten cervical cancer cell lines (21). MDM2, transformed mouse 3 T 3 cell double minute 2 , induces degradation of tumor suppressor p53 protein and inhibits apoptosis of cancer cells by p53 (22). PTGS2, prostaglandin-endoperoxide synthase 2, also known as cyclooxygenase 2 (COX-2), is known to be regulated by the human papillomavirus 16 oncogenes E6 and E7 through EGFR, and high PTGS2 expression is related to advanced diseases, distant metastases, and decreased survival in cervical cancer patients (23). VEGFA, vascular endothelial growth factor $\mathrm{A}$, is known to stimulate the growth of endothelial cells and is a powerful inducer of angiogenesis. VEGF prevents apoptosis of endothelial cells by the lack of serum and induces expression of anti-apoptotic proteins BCL-2 and A1 (24,25). The significant expression reduction of these genes that are closely related to cancer development is consistent with the results for proliferation inhibition and apoptosis of TC-1 tumor cells by combination therapy with PDT and selenium.

BRCA1, MMP10, VCAM1, BIRC2, BIRC3, and WISP1 were also significantly down-regulated in TC-1 cells with co-treatment of PDT and selenium. Deficiency of BRCA1, breast cancer associated gene 1 , causes abnormalities in the S-phase checkpoint, the G2/M checkpoint, and centrosome duplication and induces inhibition of cell proliferation and apoptosis (26). Matrix metalloproteinases (MMPs) are involved in several steps of cancer development, and MMP10 is overexpressed in head and neck SCCs (27). Expression of VCAM1, vascular cell adhesion molecule 1, in tumor cells decreases accumulation of $\mathrm{T}$ cells in the tumor site by promoting T-cell migration away from tumors. VCAM1-expressing tumor cells are able to avoid immune attack
(28). BIR2 and BIRC3, baculoviral IAP repeat-containing 2 and 3 , are known to accelerate tumorigenesis as anti-apoptotic genes $(29,30)$. WISP-1, WNT1 inducible signaling pathway protein 1 , is strongly expressed in breast tumors developing in WNT-1 transgenic mice, and overexpression in normal rat kidney fibroblasts induces their transformaiton $(31,32)$. As these genes were also related to cell cycle and transformation of tumors, downregulation of these genes would effectively inhibit development of TC-1 cancer cells.

In conclusion, we have shown that co-treatment with PDT and selenium induces growth inhibition, apoptotic morphology changes, and gene expression changes in TC-1 tumor cells. Treatment with low concentrations of PDT and selenium in combination sufficiently inhibited tumor cell proliferation without growth recovery of cancer cells following PDT alone. These effects may be due to significant down-regulation of anti-apoptotic genes and tumor-promoting genes. These results indicated that combination therapy of selenium and PDT could effectively induce a tumor suppression response compared to PDT or selenium alone. Therefore, we suggested that combination therapy using PDT and selenium can be an approach to induce effective anti-cancer effects.

\section{Acknowledgements}

This study was supported by Business of Globalization for Science and Technology funded by the Ministry of Education, Science and Technology, Seoul, Republic of Korea (Grant 5-2012-A0154-00001).

\section{References}

1. Dolmans DE, Fukumura D and Jain RK: Photodynamic therapy for cancer. Nat Rev Cancer 3: 380-387, 2003.

2. Moghissi K, Dixon K, Thorpe JA, Stringer M and Oxtoby C: Photodynamic therapy (PDT) in early central lung cancer: a treatment option for patients ineligible for surgical resection. Thorax 62: 391-395, 2007.

3. Usuda J, Kato H, Okunaka T, et al: Photodynamic therapy (PDT) for lung cancers. J Thorac Oncol 1: 489-493, 2006.

4. Klein A, Babilas P, Karrer S, Landthaler M and Szeimies RM: Photodynamic therapy in dermatology - an update 2008. J Dtsch Dermatol Ges 6: 839-846, 2008.

5. Biel MA: Photodynamic therapy treatment of early oral and laryngeal cancers. Photochem Photobiol 83: 1063-1068, 2007.

6. Dougherty TJ, Gomer CJ, Henderson BW, et al: Photodynamic therapy. J Natl Cancer Inst 90: 889-905, 1998.

7. Gollnick SO, Evans SS, Baumann H, et al: Role of cytokines in photodynamic therapy-induced local and systemic inflammation. Br J Cancer 88: 1772-1779, 2003.

8. Harrison L and Blackwell K: Hypoxia and anemia: factors in decreased sensitivity to radiation therapy and chemotherapy? Oncologist 9 (Suppl 5): 31-40, 2004.

9. Vaupel P and Harrison L: Tumor hypoxia: causative factors, compensatory mechanisms, and cellular response. Oncologist 9 (Suppl. 5): 4-9, 2004.

10. Stadtman TC: Selenium biochemistry. Mammalian selenoenzymes. Ann NY Acad Sci 899: 399-402, 2000.

11. Navarro-Alarcon $M$ and Cabrera-Vique $C$ : Selenium in food and the human body: a review. Sci Total Environ 400: 115-141, 2008.

12. Jackson MI and Combs GF Jr: Selenium and anticarcinogenesis: underlying mechanisms. Curr Opin Clin Nutr Metab Care 11: 718-726, 2008.

13. Letavayova L, Vlckova V and Brozmanova J: Selenium: from cancer prevention to DNA damage. Toxicology 227: 1-14, 2006.

14. Pletcher SD, Macdonald SJ, Marguerie R, et al: Genome-wide transcript profiles in aging and calorically restricted Drosophila melanogaster. Curr Biol 12: 712-723, 2002. 
15. Wang JL, Lin YW, Chen HM, et al: Calcium prevents tumorigenesis in a mouse model of colorectal cancer. PLoS One 6: e22566, 2011.

16. Wilson BC and Patterson MS: The physics, biophysics and technology of photodynamic therapy. Phys Med Biol 53: R61-R109, 2008.

17. Zawacka-Pankau J, Krachulec J, Grulkowski I, Bielawski KP and Selivanova G: The p53-mediated cytotoxicity of photodynamic therapy of cancer: recent advances. Toxicol Appl Pharmacol 232: 487-497, 2008

18. Buytaert E, Dewaele M and Agostinis P: Molecular effectors of multiple cell death pathways initiated by photodynamic therapy. Biochim Biophys Acta 1776: 86-107, 2007.

19. Milde-Langosch K: The Fos family of transcription factors and their role in tumourigenesis. Eur J Cancer 41: 2449-2461, 2005.

20. Peng QP, Zhou JM, Zhou Q, Pan F, Zhong DP and Liang HJ Downregulation of the hexokinase II gene sensitizes human colon cancer cells to 5-fluorouracil. Chemotherapy 54: 357-363, 2008.

21. Zijlmans HJ, Fleuren GJ, Baelde HJ, Eilers PH, Kenter GG and Gorter A: The absence of CCL2 expression in cervical carcinoma is associated with increased survival and loss of heterozygosity at 17q11.2. J Pathol 208: 507-517, 2006.

22. Hengstermann A, Linares LK, Ciechanover A, Whitaker NJ and Scheffner M: Complete switch from Mdm2 to human papillomavirus E6-mediated degradation of p53 in cervical cancer cells. Proc Natl Acad Sci USA 98: 1218-1223, 2001.

23. Ferrario A, Von Tiehl K, Wong S, Luna $M$ and Gomer CJ: Cyclooxygenase-2 inhibitor treatment enhances photodynamic therapy-mediated tumor response. Cancer Res 62: 3956-3961, 2002.
24. Bequet-Romero M and Lopez-Ocejo O: Angiogenesis modulators expression in culture cell lines positives for HPV-16 oncoproteins. Biochem Biophys Res Commun 277: 55-61, 2000.

25. Karamysheva AF: Mechanisms of angiogenesis. Biochemistry (Mosc) 73: 751-762, 2008

26. Deng CX: BRCA1: cell cycle checkpoint, genetic instability, DNA damage response and cancer evolution. Nucleic Acids Res 34: 1416-1426, 2006.

27. Yen $\mathrm{CY}$, Chen $\mathrm{CH}$, Chang $\mathrm{CH}$, et al: Matrix metalloproteinases (MMP) 1 and MMP10 but not MMP12 are potential oral cancer markers. Biomarkers 14: 244-249, 2009.

28. Wu TC: The role of vascular cell adhesion molecule-1 in tumor immune evasion. Cancer Res 67: 6003-6006, 2007.

29. Zender L, Spector MS, Xue W, et al: Identification and validation of oncogenes in liver cancer using an integrative oncogenomic approach. Cell 125: 1253-1267, 2006.

30. Ma O, Cai WW, Zender L, et al: MMP13, Birc2 (cIAP1), and Birc3 (cIAP2), amplified on chromosome 9, collaborate with p53 deficiency in mouse osteosarcoma progression. Cancer Res 69: 2559-2567, 2009.

31. Khor TO, Gul YA, Ithnin H and Seow HF: A comparative study of the expression of Wnt-1, WISP-1, survivin and cyclin-D1 in colorectal carcinoma. Int J Colorectal Dis 21: 291-300, 2006.

32. Xie D, Nakachi K, Wang H,Elashoff R and Koeffler HP: Elevated levels of connective tissue growth factor, WISP-1, and CYR61 in primary breast cancers associated with more advanced features. Cancer Res 61: 8917-8923, 2001. 